\title{
Disruptive technologies in higher education
}

\author{
Michael Flavin*
}

King's Learning Institute, King's College, London, UK

(Received 20 February 2012; final version received 20 June 2012)

This paper analyses the role of "disruptive" innovative technologies in higher education. In this country and elsewhere, Higher Education Institutions (HEIs) have invested significant sums in learning technologies, with Virtual Learning Environments (VLEs) being more or less universal, but these technologies have not been universally adopted and used by students and staff. Instead, other technologies not owned or controlled by HEIs are widely used to support learning and teaching. According to Christensen's theory of Disruptive Innovation, these disruptive technologies are not designed explicitly to support learning and teaching in higher education, but have educational potential. This study uses Activity Theory and Expansive Learning to analyse data regarding the impact of disruptive technologies. The data were obtained through a questionnaire survey about awareness and use of technologies, and through observation and interviews, exploring participants' actual practice. The survey answers tended to endorse Disruptive Innovation theory, with participants establishing meanings for technologies through their use of them, rather than in keeping with a designer's intentions. Observation revealed that learners use a narrow range of technologies to support learning, but with a tendency to use resources other than those supplied by their HEIs. Interviews showed that participants use simple and convenient technologies to support their learning and teaching. This study identifies a contradiction between learning technologies made available by HEIs, and technologies used in practice. There is no evidence to suggest that a wide range of technologies is being used to support learning and teaching. Instead, a small range of technologies is being used for a wide range of tasks. Students and lecturers are not dependent on their HEIs to support learning and teaching. Instead, they self-select technologies, with use weighted towards established brands. The use of technologies outside HEIs has implications for the monitoring of learning and teaching, and for the role of HEIs, which are no longer the gatekeepers to knowledge.

Keywords: confronting reality; problem solving; VLEs; online learning; informal learning; disruptive innovation; disruptive technology; activity theory; expansive learning

\section{Introduction}

Higher Education Institutions (HEIs) in the UK have invested significantly in digital technologies for learning and teaching; Virtual Learning Environments (VLEs) are more or less universal. However, technologies provided by HEIs have not been universally successful in terms of adoption and usage (Blin and Munro 2008; Conole et al. 2008; Selwyn 2007). Meanwhile, students and lecturers use technologies

*Corresponding author. Email: michael.flavin@kcl.ac.uk 
not owned or controlled by HEIs to support and enhance their learning and teaching.

A number of researchers have anticipated that the use of technologies in learning and teaching would disrupt learning and teaching practices in higher education (e.g., Blin and Munro 2008; Sharples 2003). However, digital technologies have, in practice, largely reproduced, rather than transformed and disrupted, existing pedagogical approaches (Fry and Love 2011; Margaryan, Littlejohn, and Vojt 2011). It is therefore appropriate to explore how non-institutional technologies contribute to learning and teaching in higher education. In order to address this issue, this paper investigates the role of "disruptive technologies" (Christensen 1997) in higher education.

\subsection{Disruptive technologies}

Disruptive technologies are those that disrupt established practices, often starting with a small number of users, but growing over time to the extent that they displace a previously dominant, incumbent technology. Conversely, sustaining technologies are technologies that enhance the performance of established technologies, as Christensen (1997) outlines:

What all sustaining technologies have in common is that they improve the performance of established products ... Disruptive technologies bring to market a very different value proposition than had been available previously ... Products based on disruptive technologies are typically cheaper, simpler, smaller, and, frequently, more convenient to use. (p. xv)

Christensen and Raynor (2003) subsequently changed the term "disruptive technology" to "disruptive innovation", arguing that the disruption is not an intrinsic feature of the technology, but, instead, emerges through practice. However, I use the term "disruptive technology" in this paper for clarity's sake, as my research is fundamentally interested in technologies for learning and teaching.

Christensen, Horn, and Johnson (2011) argue that the school system in the USA has relied on sustaining technologies, and Christensen and Eyring (2011) argue that higher education in the USA has also followed the sustaining technology approach: "Even when computers were introduced into the classroom, they were used to enhance the existing instructional approaches, rather than to supplant them. Lectures, for example, were augmented with computer graphics, but the lecture itself persisted in its fundamental form" (p. 18). In this sense, Christensen's argument repeats the findings of Blin and Munro (2008) in their study of a VLE at a campus university in Ireland. Where Blin and Munro conclude, "although use of the VLE is widespread within the university, little disruption of teaching practices ... has occurred" (2008, p. 488), Christensen et al. argue, "traditional instructional practices have changed little despite the introduction of computer and other modern technologies" (2011, p. 83).

\subsection{Activity Theory and Expansive Learning}

Expansive Learning (Engeström 1987) derives from Activity Theory, which was formulated from Vygotsky's (1978, 1927/1997) theory of human development. Activity Theory argues that human actions are not a direct transmission between subject and object, but are mediated through the use of (broadly defined) tools. 


\section{Flavin}

Activity Theory is an appropriate lens for this paper because it enables an exploration of how digital technologies impact on other aspects of higher education, including social relations. Scanlon and Issroff (2005) have previously used Activity Theory to analyse the impact of technologies in higher education, and, at a school level, Hardman (2005) used Activity Theory to analyse the impact of technology in teaching mathematics in deprived communities in South Africa. In both cases, the researchers noted the impact of new technologies on the division of labour within a classroom setting. Vygotsky (1978) represented the first generation model of human activity as a simple triangle (Figure 1). Vygotsky's model illustrates his theory that human beings do not interact directly with their environment. Instead, they use tools (including signs and codes as well as physical apparatus) as mediators.

Engeström (1987) developed the expanded model of human activity (the activity system) to include and highlight the collaborative nature of human activity by adding social elements to Vygotsky's original model of human activity, as shown in Figure 2.

The bottom row of the triangle (the layer added by Engeström) features the rules, the community and the division of labour as its nodes. The rules node represents the conventions and regulations shaping an activity (such as assessment within an education system). Community refers to those affected by the activity, and the division of labour node represents who does what in an activity, thereby illustrating both the distribution of tasks, and the hierarchy of power.

There can, however, be contradictions in the interaction of the nodes, and it is these contradictions that Engeström (1987, 2001) identifies as significant in Expansive Learning, as the contradiction can enable the construction of new knowledge. For example, a lecturer works with students with the intended outcome of high-quality learning. Digital technologies (tools) can be used to facilitate the learning. However, if a new tool is available, over which the students (rather than the lecturer) have mastery, this may require new practices within the activity system in order for the object of high-quality learning to be accomplished, as was observed by Scanlon and Issroff (2005). When digital technologies are brought into a classroom setting, the lecturer may have to relinquish some of their authority (thus impacting on the "rules" and "division of labour" nodes) in order to enable enhanced learning. The analysis overlaps with Christensen's Disruptive Technology theory (1997) in the sense that a new technology can disrupt existing practices (and thereby risk rejection), but also that the new technology can go on to change the practice itself.

A feature of Engeström's approach is that tools do not need an instruction manual: "A tool always implies more possible uses than the original operations that have given birth to it" (1987), and "the material form and shape of the artifact [sic]

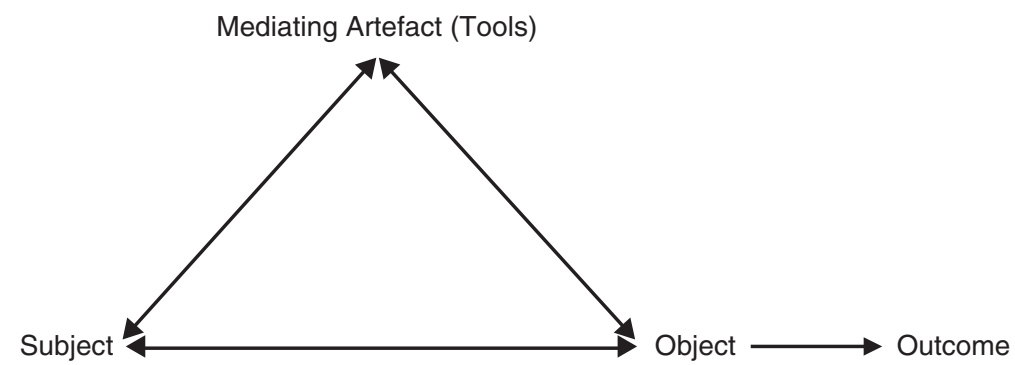

Figure 1. First-generation activity system (based on Vygotsky 1978). 


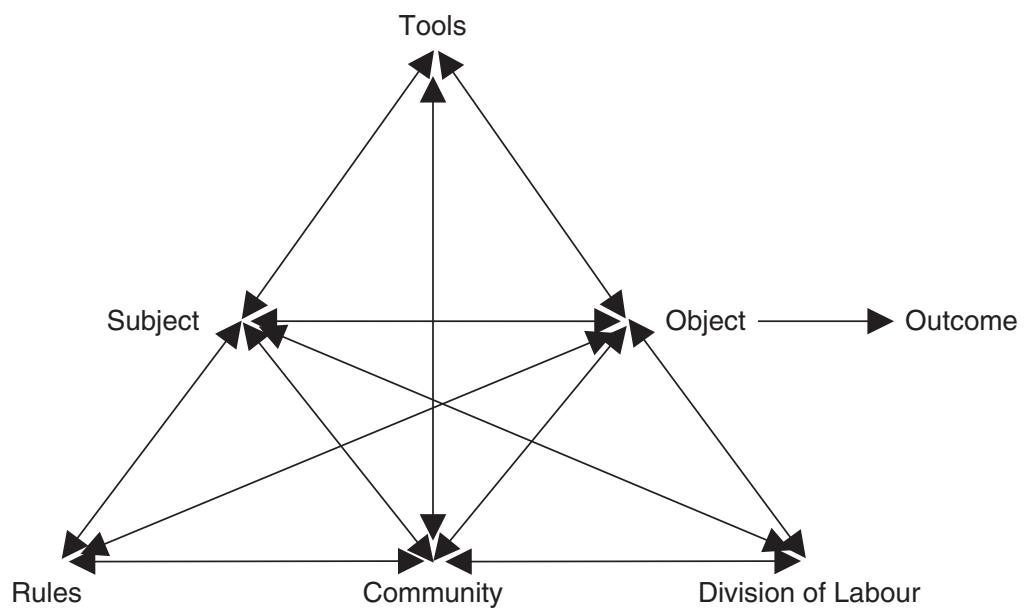

Figure 2. Second-generation activity system (based on Engeström 1987).

have only limited power to determine its epistemic use" (2007, pp. 34-35). This leads Engeström to conclude, "In Expansive Learning ... reconfiguration of given technologies by their users is essential" (2007, p. 35). Engeström's argument implies that people establish the meanings of technologies through their uses of them. Meaning is not constrained by design.

\section{Research methodology}

This study focuses on understanding the role of disruptive technologies in higher education learning and teaching.

From November 2010 to March 2011 a pilot survey was conducted, using a questionnaire comprising tick box questions and open-ended queries. The questionnaire explored the following issues: (1) What technologies are participants aware of?, (2) What do participants use technologies for? and (3) To what extent do participants use technologies for more than one purpose? The survey yielded baseline data about technology use, and which technologies were used most widely and for more than one purpose. Of the 28 people surveyed 13 were undergraduates, four were postgraduate students and one was a postgraduate researcher. The survey also included six lecturers and four academic-related staff.

The original questionnaire was revised to include technologies that did not feature in the pilot study questionnaire. A new survey took place in OctoberNovember 2011. Twenty questionnaires were returned by 15 undergraduate students, one postgraduate researcher, two lecturers and two academic-related staff. None of these respondents was from the first sample.

Seven observation studies were conducted in October-November 2011. The participants (four students and three lecturers) were given a task concerning the identification and storage of information to support learning and teaching, and their responses to the task were recorded by the researcher.

Furthermore, five interviews were conducted in December 2011-January 2012. Two were semi-structured and focused largely on the use of specific technologies. The remaining three interviews were structured, exploring the use of technologies more broadly. 


\section{Findings and discussion}

\subsection{Questionnaire surveys}

The pilot survey findings showed that individual technologies were being used for more than one purpose. For example, Facebook was used for recreation by 16 participants, but also for work (seven) and informal learning (three), with informal learning signifying learning not undertaken in the context of a formal course. Twitter was used for recreation by 10 participants, but also for work (seven) and informal learning (five). The pilot questionnaire replies also showed respondents' limited awareness of emerging technologies; 21 participants had not heard of Wallwisher, Xtranormal or Prezi, and 13 participants had not heard of Delicious.

The pilot survey findings for Wikipedia indicated its ubiquity: 21 participants used it for recreation, 20 for informal learning, 15 for formal learning and 16 for work. One participant wrote, "Wiki[pedia] often comes up as the first port of call for quick research, but due to it's [sic] unreliability I would usually try to corroborate any information found there". Another participant wrote, "I wouldn't blindly trust the articles themselves as reliable sources of information" and a further participant wrote, "I'm always wary about the veracity of the information". It is noteworthy that the use of Wikipedia is not prevented by its perceived unreliability, as it is a readily available tool to serve a purpose, and hence has a role within an Activity Theory framework.

The pilot survey suggested that users create their own purposes for Wikipedia. In addition, Wikipedia has challenged more established encyclopaedias, which can be classed as a sustaining technology because they update their knowledge along existing lines and within similar publication formats, but are challenged by a rival online encyclopaedia which is free, and readily available. One participant stated, "The biggest advantage of Wikipedia is that the answers are at your finger tips, you can ask a question and the answer appears without the need for flicking from chapter to chapter in a book". Like many disruptive technologies, Wikipedia is cheaper (free in this particular case), simpler, smaller and more convenient than its more established rivals.

The second survey showed respondents' low awareness of new technologies that can be used to support learning and teaching: participants tended to rely on wellestablished technologies. For example, 19 of the 20 participants had not heard of Xtranormal, 17 had not heard of Wordle or Wallwisher, and 15 had not heard of Delicious or Prezi.

The second survey also showed that 17 participants from the second sample used Wikipedia for informal learning, 15 for recreation, 12 for work and 10 for formal learning. These findings mirrored the findings of the first survey, in the sense that participants shaped their own purposes for technologies, using individual technologies for a range of purposes. Moreover, participants relied on a few technologies. One participant stated, "Adding too many technologies to support teaching/ learning, especially where one or two can do the job well, can overwhelm the student (and the educator!)". From an Activity Theory perspective, a plethora of tools can cause tension between the subject (the learner) and the object (the learning); learners benefit from clear and simple guidance on how to use digital technologies to support their learning.

In both surveys only one respondent had used Second Life. In the second survey, the participant who used Second Life did so in their role as a research student: again, 
it is noteworthy that the purpose was determined by the user, not by a designer's intentions. Second Life is a technology with a relatively steep learning curve, but almost all the participants used Wikipedia, which is conspicuously easy to use, not least because it is an encyclopaedia, a familiar type of publication. Second Life, a virtual world, calls for some acclimatisation before users can make optimal use of it. Wikipedia conforms to Christensen's definition of a disruptive technology, but Second Life lacks Wikipedia's simplicity.

\subsection{Interviews}

In February 2011, two participants in the first survey were each introduced to a technology they had not previously heard of, then given time to incorporate this technology into their practice. They were interviewed 10 months later, in December 2011, regarding their use of the new technology, and their use of technologies more generally.

The first respondent (a lecturer) had been introduced to Delicious (free online bookmarking service) by the researcher, but not given instruction on how to use it. In the 10 months, she had used Delicious frequently, with use of the tool expanding to include her family, and her wider social network. She related her experience to the ease of use of Delicious: "I think it was a fairly rapid adoption. I wouldn't call myself somebody who was naturally proficient in technology, but it was very much an instinctive environment". Delicious conforms to Christensen's definition of a disruptive technology (1997), as it is easy to use. It is also convenient and free.

This respondent was also asked about her perceptions of her undergraduate students' uses of technologies to support learning, three months into the academic year.

They have got access to [name of HEI] virtual learning environment. Some of them have been fairly swift to embrace that. Others still have not logged-on, which is a concern as even in the induction week we showed them how to do it ... So some are not as technologically proficient as we thought they would be. Others are extremely adept. We did some presentations earlier this week; they were quite happy hyperlinking to YouTube and other sites. Similarly they are quite happy to sit down and work with their own laptops or iPads and conduct research there - in fact they prefer to do that than rifle through the core text, even when you tell them that the information is there in the core text. They instinctively jump onto what they are more familiar with.

While the interview did not explore ideas concerning why the students were not all accessing the institutional VLE but making frequent use of other technologies, it is noteworthy that the students appear to have their own preferred technologies for learning, which are not necessarily the learning technologies supplied by their HEI.

During interview the second respondent (a learning technologist and postgraduate student) was asked whether she had used Wallwisher, a free online notice board to which she had been introduced by the researcher. The participant had not used Wallwisher, stating, " ... like with all of these things, unless everyone else is using it, it doesn't perhaps fulfill its potential ...". She was unable to construct a personal meaning for the technology, which thus remained unused. Moreover, she was put off by the fact that other people were not using the technology. A critical mass may be important for the widespread adoption of a technology, perhaps through marketing that can create a community of users. Innovative uses of technologies to support 


\section{Flavin}

learning can possibly be manufactured, an argument laid out in Markides's (2006) critique of Disruptive Innovation.

\subsection{Observation studies}

In the observation studies, participants were given a task concerning the identification and storage of information to support learning and teaching. Of the seven participants four were students who were given the following task:

You have been asked to write an essay for assessment at a H.E. Institution, concerning the issue of widening participation in H.E. Identify, gather and store relevant information for this essay, using only the computer in front of you. Do this for fifteen minutes.

The remaining three participants were lecturers, and were given the following task:

You have been asked to prepare a class on emergent forms of assessment in H.E. Identify, gather and store learning and teaching materials for this purpose, using only the computer in front of you. Do this for fifteen minutes.

The participants in both groups used a narrow range of technologies, perhaps unsurprisingly given the short time available to them. The most common approach, adopted by five of the participants, involved doing most of the research via Google, with results (text or URLs) saved to a blank Word document and saved in My Documents. Four participants used an academic journal aggregator made available by their HEI, but one of those four went to the journal aggregator after having undertaken their initial search on Google. Only one participant used Delicious to store and tag web links; five copied links to a blank Word document, and one emailed links to herself, via a facility made available on the academic journal aggregator.

Participants did not look beyond the first two pages of results obtained on Google, and five participants did not go beyond page 1 of results on either Google or Google Scholar. It appears users want and expect quick results, and value ease of access (in line with Christensen's argument), though the participants' actions may also have been shaped by the short time allowed for the tasks.

Three participants used Google Scholar. Six of the seven used Google. One participant entered search terms in a search box on her HEI's home page. The results came up provided by Bing. The participant clicked off Bing without looking at the results, and repeated the same search on Google. It appeared the participant had a preferred brand, and was not interested in trying another. Seeing technology in terms of brand choices links in with Markides's (2006) critique of Disruptive Innovation: he argues that innovations and disruptions in technologies are shaped more by effective marketing than by spontaneous creativity.

While the two observation studies show participants using a narrow range of technologies, all the participants were able to undertake the task. The technologies selected were able to do the job, hence students did not use other technologies. Technologies are being used flexibly, and in some senses disruptively because the user creates a purpose for the technology, but the evidence from the observation studies suggests that a limited range of technologies is being used to support learning and teaching, a conclusion also drawn by Margaryan, Littlejohn, and Vojt (2011) and Jones and Healing (2010) in their studies of students' uses of technologies to support learning. 
From an Activity Theory perspective, the observation studies show technology, as a tool, impacting on other nodes within the activity system. In particular, the social nodes in Engeström's activity system triangle (rules, community and division of labour) are affected by how technologies are being used to support learning and teaching. Learners are no longer reliant on reading lists supplied by lecturers, and use other sources to support their learning. Therefore, the role of the HEI as gatekeeper to knowledge is altered, as material can be accessed any time and from anywhere.

\subsection{Structured interviews}

Three structured interviews were conducted in January 2012. Each of the interviewees (a lecturer and two students) was asked questions relating to their uses of technologies to support learning and teaching, including "Where do you get the learning materials you use for work you submit for assessment?" to the students, and "As a Lecturer, in your opinion, where do students get the resources they use for assessed work?" to the lecturer. One participant (the lecturer) stated that her students relied on Google for finding learning materials, and rarely used an academic journal aggregator. The postgraduate student stated that she used Google and Google Scholar to support her set texts. The lecturer also stated that she preferred Google Scholar to her HEI's academic journal aggregator: "I don't find it as user-friendly as I find Google". The interviews suggest that the participants do not see their HEI as the gatekeeper to knowledge. The participants go to Google, rather than to their HEIs' journal aggregators, for information to support learning and teaching. The lecturer indicated that ease of use was a factor as to why she opted for Google. Google, therefore, may be a disruptive technology in its own right, in that its convenience and ease of use puts it ahead of an HEI's own resources. Google, in this context, also affects the academic community and the division of labour within it, by providing an alternative route to knowledge, and implicitly challenging the HEI's custodianship of knowledge.

\section{Conclusion}

There is no evidence arising from the surveys or interviews to suggest that a wide range of technologies is being used to support learning and teaching in higher education. Instead, a narrow range of technologies is being used to undertake a wide range of tasks, with the use of Wikipedia and Google being particularly common. As Christensen's theory predicts, people prefer to use technologies that are free and easy to use. If technologies are kept simple, people are more likely to use them.

Markides (2006) is a useful source for understanding why particular technologies build a critical mass of usage. Data from the survey, observation and interviews reported here suggest that both students and lecturers have preferred technology brands. Markides's argument implies that disruption does not arise organically, but that markets for disruptive technologies can be created through astute practice. For example, the encyclopaedia is an established form of publication, but Wikipedia has changed how an encyclopaedia (and, arguably, knowledge more widely) is produced, distributed and used. Hence, Markides's analysis does not necessarily contradict Christensen's, as disruption is partly about users creating their own purposes for technologies through practice. Disruption does not arise from the intrinsic features of 


\section{Flavin}

the technology (Christensen and Raynor 2003); practice does not occur in a vacuum but is shaped by underpinning economic and social factors.

From an Activity Theory perspective, Wikipedia is a tool that disrupts the rules node of the activity triangle, and the division of labour node. Students are not solely reliant on their HEI for learning. Activity Theory also suggests that the gatekeeper role of both lecturer and HEI is changing. There are alternative routes to acquiring knowledge, and they are easy to use, convenient and often free. The same cannot always be said of learning technologies supplied by HEIs. The disruptive use of technologies also has implications for the monitoring of learning, and for the division of labour within higher education, because of the plethora of alternative pathways to knowledge challenging, implicitly, the role of the lecturer.

Further research may be able to inform the strategic development of library services in HEIs, as the research has implications for how knowledge is accessed. Further research could also explore the breadth of participants' technology choices, and the extent to which participants' choices in this regard are shaped by the effective marketing of technologies.

\section{References}

Blin, F. \& Munro, M. (2008) 'Why hasn't technology disrupted academics' teaching practices? Understanding resistance to change through the lens of activity theory', Computers and Education, vol. 50, pp. 475-490.

Christensen, C. M. (1997) The Innovator's Dilemma: When New Technologies Cause Great Firms to Fail, Harvard Business School Press, Boston, MA.

Christensen, C. M. \& Eyring, H. J. (2011) The Innovative University: Changing the DNA of Higher Education from the Inside Out, Jossey-Bass, San Francisco.

Christensen, C. M., Horn, M. B. \& Johnson, C. W. (2011) Disrupting Class: How Disruptive Innovation Will Change the Way the World Learns, McGraw Hill, New York.

Christensen, C. M. \& Raynor, M. E. (2003) The Innovator's Solution: Creating and Sustaining Successful Growth, Harvard University Press, Cambridge, MA.

Conole, G., et al. (2008) 'Disruptive technologies', 'pedagogical innovation': what's new? Findings from an in-depth study of students' use and perception of technology', Computers and Education, vol. 50, pp. 511-524.

Engeström, Y. (1987) Learning by Expanding: An Activity-theoretical Approach to Developmental Research, Orienta-Konsultit Oy, Helsinki. Available at: http://lchc.ucsd.edu/MCA/ Paper/Engestrom/expanding/toc.htm.

Engeström, Y. (2001) 'Expansive Learning at Work: toward an activity theoretical reconceptualization', Journal of Education and Work, vol. 14, no. 1, pp. 133-156.

Engeström, Y. (2007) 'Enriching the theory of expansive learning: lessons from journeys toward coconfiguration', Mind, Culture and Activity, vol. 14, no. 1-2, pp. 23-39.

Fry, N. \& Love, N. (2011) 'Business lecturers perceptions and interactions with the virtual learning environment', International Journal of Management Education, vol. 9, no. 4 , pp. $51-56$.

Hardman, J. (2005) 'An exploratory case study of computer use in a primary school mathematics classroom: new technology, new pedagogy?', Perspectives in Education, vol. 23 , no. 4, pp. 1-13.

Jones, C. \& Healing, G. (2010) 'Net generation students: agency and choice and the new technologies', Journal of Computer Assisted Learning, vol. 26, pp. 344-356.

Margaryan, A., Littlejohn, A. \& Vojt, G. (2011) 'Are digital natives a myth or reality? University students' use of digital technologies', Computers and Education, vol. 56, pp. 429-440.

Markides, C. (2006) 'Disruptive innovation: in need of better theory', The Journal of Product Innovation Management, vol. 23, no. 1, pp. 19-25.

Scanlon, E. \& Issroff, K. (2005) 'Activity Theory and Higher Education: evaluating learning technologies', Journal of Computer Assisted Learning, vol. 21, pp. 430-439. 
Selwyn, N. (2007) 'The use of computer technology in university learning and teaching: a critical perspective', Journal of Computer Assisted Learning, vol. 23, no. 2, pp. 83-94.

Sharples, M. (2003) 'Disruptive devices: mobile technology for conversational learning', International Journal of Continuing Engineering Education and Lifelong Learning, vol. 12, no. 5-6, pp. 504-520.

Vygotsky, L. S. (1978) in Mind in Society-The Development of Higher Psychological Processes, eds M. Cole, V. John-Steiner, S. Scribner \& E. Souberman, Harvard University Press, Cambridge, MA, USA.

Vygotsky, L. S. (1927/1997) 'The historical meaning of the crisis in psychology: a methodological investigation', in The Collected Works of L. S. Vygotsky, Vol. 3: Problems of the Theory and History of Psychology, eds R. W. Rieber \& J. Wollock, Plenum, New York. 